\title{
Analysis of Greek Textbooks about Marine Biology
}

\author{
Panagiotis K. Stasinakis ${ }^{1^{*}}$
}

\author{
${ }^{1}$ Ampelokipoi Laboratory Centre for Natural Sciences, GREECE \\ *Corresponding Author: stasinakis@biologia.gr
}

Citation: Stasinakis, P. (2021). Analysis of Greek textbooks about marine biology. Interdisciplinary Journal of Environmental and Science Education, 17(2), e2234. https://doi.org/ 10.21601/ijese/9336

$\begin{array}{ll}\text { ARTICLE INFO } & \text { ABSTRACT } \\ \begin{array}{l}\text { Received: } \\ \text { 30 September 2020 }\end{array} & \begin{array}{l}\text { Greece is located at the southeastern edge of the European Union, surrounded by coastline that } \\ \text { reaches 18 thousand kilometers. This study aims to analyze educational material, the textbooks used } \\ \text { in secondary education - Gymnasium - to determine whether students and future citizens of the country } \\ \text { are taught in depth issues related to Marine Biology. Analyzing content, applying biophilic typology and } \\ \text { 30 November 2020 }\end{array} \quad \begin{array}{l}\text { recording observations, reveals several positive points and weaknesses that require improvements. } \\ \text { The analysis recognizes the need for a more organized approach to Marine Biology issues, to be more } \\ \text { actively integrated into teaching. }\end{array}\end{array}$

Keywords: marine biology, secondary education, textbook, Greece

\section{INTRODUCTION \\ The Greek Sea}

The Aegean is comprised from more than 3000 islands and islets and is a distinctive Mediterranean habitat with morphological diversity. It has plateaus and deep gorges, it has variety of habitats, with alternating rocky coasts, sandy coasts, meadows of algae fundus, coral formations and sea caves. The variability of habitats in combination with the specific temperature, salinity and the water circulation system, reflects in the biotic environment which is rich and comparable with other northern Mediterranean sub-regions, like Adriatics. The Aegean Sea hosts many meadows of Posidonia oceanica, Cystoseira colonies in the shallow reefs, the biggest population of Monachus in the Mediterranean Sea, high benthic variety in soft sediments (especially in lagoons and in estuaries' habitats), rich benthic communities in coral and cave habitats, including rare endemic species and invertebrates of commercial value like sponges, precious corals and dense populations of small cetaceans (Voultsiadou, Gerovasileiou, \& Dailianis, 2013).

The Greek coastline reaches 18 thousand kilometers. During the last years, the Greek scientific community is trying to record all the natural wealth of the land and the fresh waters. The first efforts which begun in 1980 and were completed in 2000, showed that 23000 taxa which after processing and reduction reached 4000050000 (Arvanitidis, 2018). After that two more projects, 'Greek Biodiversity Database' from the Department of Zoology (focusing on the marine biodiversity), School of Biology, Aristotle University of Thessaloniki and the 'LifeWatchGreece' in which fresh regions were included as well as those of the Marine Exclusive Economic Zone, has recorded until now 35 thousand taxa, approximately 1000 more than the previous program (Arvanitidis, 2018). The National Index of Habitats and Species of European Interest, has listed 9 marine and 80 water and land habitats (UH, 2018). However, this huge diversity is threatened with extinction since a variety of marine taxa suffer from reduction rates in their population like the marine mammals, the cetaceans, the elasmobranchii chondrichthyes, the sea turtles and invertebrate populations like sponges, corals and mollusca (Voultsiadou, Gerovasileiou, \& Dailianis, 2013). Besides scientific reasons (e.g insufficient scientific data) it is observed (Voultsiadou, Gerovasileiou, \& Dailianis, 2013) that the lack of environmental awareness consists of additional, potential threat for the vulnerable species: for example despite the legal status regarding the commercial exploitation of elasmobranchii, big sharks (e.g. Cetorhinus maximus) are fished and sold in Greek fish markets.

Many algae grow in the Greek rocky coasts. Although 
they may be confused with other sea plants (angiosperms, seagrass like Posidonia, Cymodocea, Zostera), big algae (macroalgae), and tiny algae (microalgae), create marine gardens. Oceans in total account produce about the $50 \%$ of the atmospheric oxygen, through photosynthesis (Chapman, 2013). The rocky coasts are dominated by green, brown and red algae, which are easily identified and observable. The microalgae participate in the phytoplankton like the diatoma, pyrrhophyta, etc. In Greece due to the existing ecological conditions, the big red and brown seaweeds are developed mostly Cystoseira, Padina, Laurencia, while in not very clean waters the green algae Ulva (known as the 'lettuce of the sea') (Hellenic Phycological Society, 2008; Stasinakis, 2009).

\section{Marine Biology (MB) Teaching in the Secondary Education (SE)}

Van de Born, Lenders, De Groot, and Huijsman (2001) note that people who have experiences with nature in their early life have a friendlier attitude to nature as adults. Burgess and Mayer-Smith (2011) confirm that direct contact of the students with nature, helps them develop a friendlier position towards the natural environment.

The beliefs and attitudes towards nature can be developed both with formal and informal education. Liarakou (2008) conducted a study with 314 lower school students in the island of Samos regarding whether the jackals in Samos should be protected or not in order for its population to recover. In that study, $74.5 \%$ of the students replied positive, $20.5 \%$ replied negative while the rest $5 \%$ did not answer at all. She used in this study the Biophilic Typology (BiTy) of Kellert and Westervelt (1983), a methodological approach with 10 (ten) basic categories of beliefs and attitudes towards nature:

- Naturalistic, which is related to personal interest, curiosity and a sense of discovery of the wildlife.

- Ecologistic, which emphasizes on the systematic study of the structure and the function of the relationships that evolve in nature.

- Humanistic, which is related to the compassion and the emotional bonding with nature, based on anthropocentric findings.

- Moralistic, which is linked to the moral interest for our behavior in nature and the spiritual respect.

- Scientific, which is related with the natural properties and the biological functions.

- Aesthetic, which is related to the natural beauty, nature's charm and the symbolic characteristics of organisms.

- Utilitarian, which is based on the benefits that people can have from the exploitation of nature regarding the production of products, materials etc.
- Dominionistic, which expressed the desire for the domination and control of the natural world.

- Negativistic, which is related to fear, dislike and alienation towards nature, characteristics that are more obvious to certain species of the natural world.

- Neutralistic, which refers to a passive attitude towards nature either due to indifference or due to the lack of preoccupation.

Kim, Anderson \& Scott (2013) highlight the importance of the students' experiences in relation to MB. They note that the biggest part of their experience comes from TV programs, movies and books rather than direct contact with organisms. Usually, they have direct experiences with 'gulls', 'fish' and 'crabs' in their natural environments. More than half of the students have experiences with dolphins in non-natural environments, like zoos or aquariums. Very few students have experiences either direct or indirect with 'sea worms', 'sea anemones', 'sea lettuces' and 'plankton'. Students have a stronger connection with 'fish', 'crabs', 'sea lettuces', a moderate connection with 'gulls', 'dolphins', 'jellyfish', 'plankton' and 'starfish', while a soft connection with 'sea turtles', 'sea worms' and 'sea anemones'. Using the BiTy of Kellert \& Westervelt (1983), they found that the $23 \%$ of the students have a Utilitarian attitude, while $2,5 \%$ of them have an Aesthetic attitude. Their analysis reveals that the dominant attitudes are the Utilitarian (due to the fish, crabs and sea lettuces), the Negativistic (due to anemones and sea worms) and the Scientific (due to sea anemones and plankton), while the Aesthetic, Humanistic, Moralistic are missing. Also dominant is the Naturalistic (due to sea turtles) and Dominionistic (due to dolphins and gulls). It seems that nutrition (fish, crabs and sea lettuces in Korean cuisine) explain the Utilitarian attitude, while the perception that anemone is a dangerous animal (84\% of the students) explains the Negativistic. The body shape and the ugly look of the sea worms, for more than half of the students is responsible for their negative attitude.

Sakurai, Uchara \& Yoshioka (2018) note that the participation of the students in educational programs for MB helps the students gain knowledge about marine biodiversity and ecosystem (like how the restoration of the sea Zoster meadows contributes to the improvement of the ecosystem) and the relationship between the humans and the sea. Furthermore, the improvement is even bigger when students are actively involved in field activities for MB. Consequently, many students change their attitude (for example they recognize the importance of the sea and the sea Zoster), while their motivation to keep the sea clean and rehabilitate the environment becomes stronger. It was found that the contact of the students with marine professionals helped towards this 
direction.

Van Bressem et al. (2006) evaluated the effectiveness of an educational program from the Peruvian Centre for Cetacean Research. The research included the visit to a museum of 55 students of the primary education and concluded that $77 \%$ of them responded correctly to 16 questions related to marine organisms and their environments. $83.7 \%$ of the students responded that the material of the museum was good to very good, $89.1 \%$ believed that it is mandatory that the marine organisms must be protected and a $98.2 \%$ hoped that they could attend more educational programs as well as visit the museum again. Moreover, the positive results had an impact in the local society: adults and children from villages where the program was executed for longer periods showed increased interest, a bigger desire for knowledge and a bigger sensitivity for cetacean and other protected marine species.

Donert et al. (2015) note that there is a limited number of publications in relation to the teaching of oceans and seas in the secondary education. Extended searches resulted in 35 publications in total between 1974 and 2015, without any significant meta-analysis or reviews. 19 of those come from the USA, 5 from Europe (England, Greece, Portugal, United Kingdom), 4 from Asia (Taiwan, Japan, Philippines, countries of the Pacific Ocean), 4 from Canada and 3 of no special origin. The report shows that in the secondary education the subjects of the sea and the oceans are rarely taught and do not appear often in curriculum, in the educational material, school textbooks, reviews or templates. The education research has revealed a small interest in MB subjects and this lack of interest demonstrates the need for education for $M B$ even among adults. As often noted, it is shown that the use of dynamic visual applications or multimedia elements creates a bigger interest and dynamic for learning than static images and textbooks. Finally, it is also demonstrated in the study the need for advice and guidance to the policy-makers, in order that they can get help to develop and suggest documentation, educational material and courses, so that the MB is also included in the curriculum, in the textbooks and in the evaluation.

In the Greek bibliography, the study of Mironaki (2016) lies in two axes: a) the analysis of school textbooksin regard to the words' number and the frequency of information in relation to $M B$ as well as the frequency of images, meanings and functions of $M B$, and $b$ ) the record of the knowledge and perceptions of students of the A class of upper high school (Lyceum), living in Dodecanese islands in relation to MB. The analysis of the textbooks confirms that in the A class of lower high school (Gymnasium), there is a small percentage $(0.15 \%)$ of references in total to words and phrases about MB. Only the $14.6 \%$ of the total pages are referred to $M B$, with emphasis in marine functions and phenomena $(0.016 \%)$ and without any references in sea plants, solutions, and activities for conservation. $7 \%$ of images in total are related to MB, with emphasis to marine functions and phenomena (5.1\%). In the textbook of the $C$ class of Gymnasium, there is a small percentage $(0.05 \%)$ of references in total to words and phrases about MB. Only the $3.8 \%$ of the total pages are referred to MB. $7.8 \%$ of images in total are related to $\mathrm{MB}$, while there is a small percentage $(0.97 \%)$ of references in conservation solutions and activities.

The findings of Mironaki (2016) are also interesting in her analysis of a sample of 918 students in Dodecanese islands investigating their knowledge and perceptions in relation to MB. The students (in a Likert 5-grade scale) do not feel satisfied from the information they get in relation to MB (2.47), while they get informed for MB subjects mainly from the internet (4.01), TV (3.21), the Biology teacher (3.18) and to a lesser extent form the Biology textbook (2.76). In the knowledge investigating questions it is indicatively noted that: a $46.5 \%$ considers that dolphins and sharks are mammals, only a $36.4 \%$ responds that the penguin is a bird with bones and knees, only a $33.3 \%$ responds that Caretta caretta has bones, lungs and gives birth to eggs, while a $59.4 \%$ responds that it is a mammal in danger of extinction, a $80.4 \%$ gives a wrong answer in relation to hydra (this has a special interest while for hydra there are analytical references in the textbooks), a $28.9 \%$ identifies algae with seagrass, a $71.1 \%$ does not recognize corals and a $77.6 \%$ sponges as sea animals, a $63.7 \%$ cannot distinguish cuttlefish from squid. Only 3 students $(0.3 \%)$ respond correctly to all 31 knowledge investigation questions (in total boys respond more correctly than girls). Through synthesis of the studies it was revealed that the students who were taught MB from formal education textbooks had a limited knowledge and a low understanding capacity for MB. Finally, it is worth noting that the knowledge and perceptions of the students do not differentiate according to whether they have participated in a project of Environmental Education (EnEd) relative to the sea.

The coexistence of humans and marine organisms has always been problematic and needed special education and culture for it to be feasible. Usually the culture of attitudes, knowledge and opinions occurs in the first years of age both in formal and non-formal education. Does the Greek formal education have the potential to give to the Greek citizens, a culture friendly to the marine organisms? The answer to this question is the objective of this study. 


\section{MATERIALS AND METHODS}

In our analysis, we used the content analysis method (Berelson, 1952). The choice of this type of analysis was done so that we could identify material relevant to MB, to do a qualitative record and be able to have a material that can also be used for quantitative analysis as well. For that reason, we created categories for the material recording forms, just as they are represented in the textbooks.

The specific research focused on the analysis of the textbooks used in the secondary education and lower high school - Gymnasium (A, B and C class). Data was collected regarding the body text of the textbooks, as well as in the extra insertions in the textbooks (information boxes, projects, exercises, etc.). In addition, images related to MB were recorded, while in some cases it was found that the expressions were possibly causing a misunderstanding to the students. Finally, the BiTy was used in order to evaluate the presentation of the recorded reports.

We aimed both to quantitative but also qualitative evaluation of the records. Since, in the teaching practice, the textbook is the basic material on which learning is based (Stasinakis \& Koliopoulos, 2009), while even the use of the additional proposed material (extra topics, suggestions for work and additional study, exercises, etc.) is not obligatory and lies at the discretion of the teacher. In addition, we have seen which of our recordings will eventually be taught based on the instructions of the Ministry of Education (2018), while finally we have recorded the incidence (direct or indirect) of concepts terms related to $\mathrm{MB}$.

The research questions we raised were:

- Is the literacy of the students in compulsory SE for MB cultivated?

- Do the textbooks cover the literacy (understanding of the sea's influence on students - and their influence on the sea) in relation to MB?

- At what frequency do the MB terms show in the textbooks of the compulsory SE?

\section{Data Collection}

For the analysis we used the textbooks Mavrikaki, Gouvra, and Kambouri (2016a), Biology of A ClassGymnasium, and Mavrikaki, Gouvra, and Kambouri (2016b), Biology for the B \& C Class - Gymnasium. These textbooks are taught in both the morning and night classes of Gymnasium. For the school year 2018-2019 according to the instructions of the Ministry of Education (in class A is taught the 'Textbook - Biology for A-class of Gymnasium', in class $C$ is taught the 'Textbook - Biology for B- \& C- class of Gymnasium', in class B chapters/units from the two textbooks), the following sections will be taught as shown in Figure 1:', instead of 'According to the instructions of the Ministry of Education (2018) for the school year 2018-2019, the following sections will be taught as shown in Figure 1.

In the C Class-Gymnasium the syllabus is the same in morning and night schools, while it is different in the $A$ and the B classes. In the A morning class, the biology lesson is taught one teaching period (45 minutes) per week, while in the A night class it is taught two teaching periods per week. In the B class morning/night, it is taught one teaching period per week, in the C class morning/ night it is taught one teaching period per week.

According to the Hellenic Statistical Authority (2018)

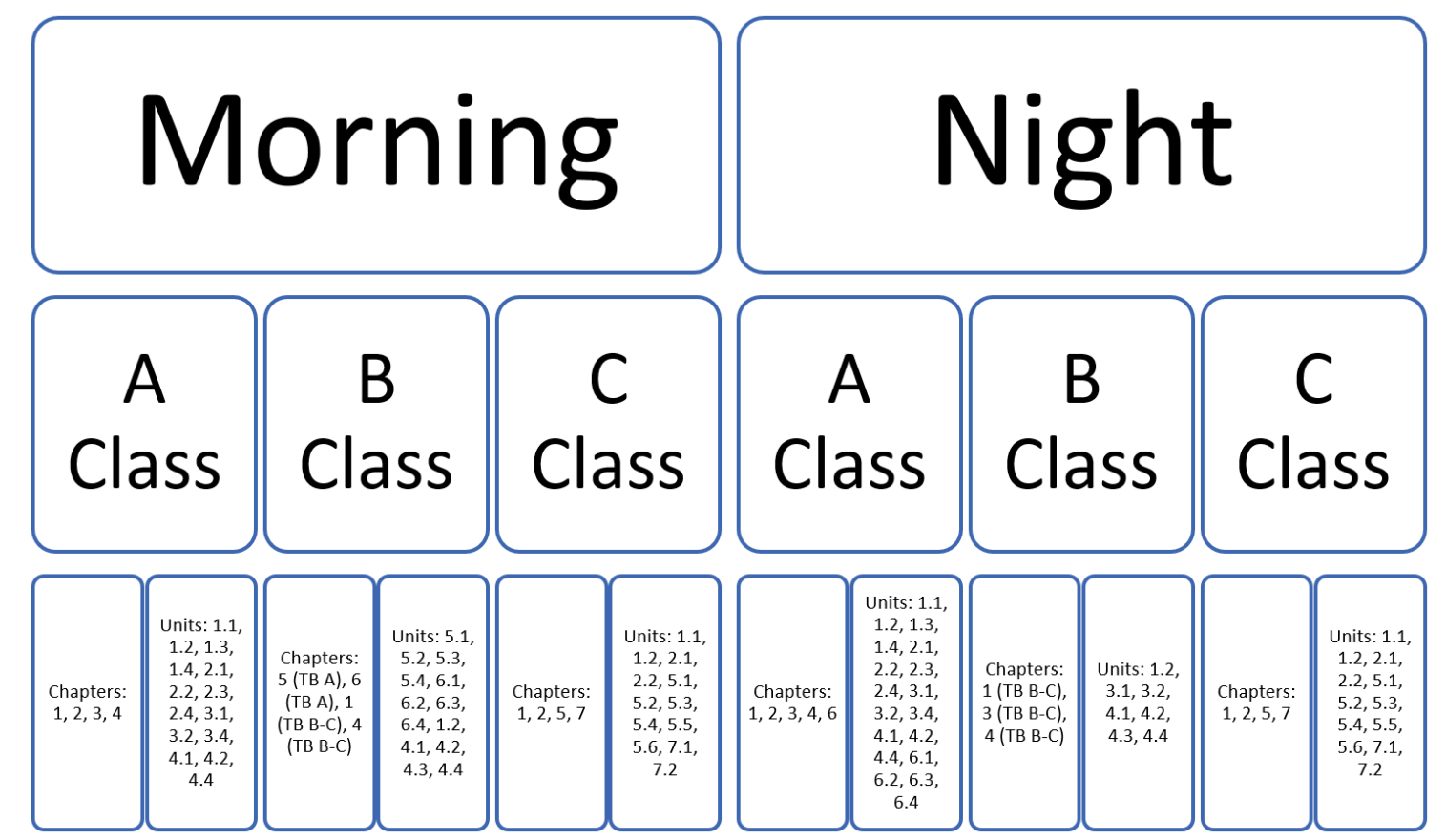

Figure 1. Syllabus units and chapters, for the school year 2018-2019 (TB: textbook) 
in the school year 2015-2016 there were 1727 public lower high schools (of which 72 were night schools) and 99 were private lower high schools, where in the public lower high schools attended 297156 students (of which the 4,915 in the night schools) and 14296 in private lower high schools. In total there were 1826 lower high schools where 311452 students attended.

\section{RESULTS}

For the analysis a grid was used. The table consists of six (6) columns.

- A/A: Serial number of recording,

- Reference: Recording of the full text in the textbook,

- Format/Typology: If the reference is Text (refers to the text in the normal flow of the school handbook), Caption (refers to the text accompanying an illustration or an image) + Illustration (refers to sketches, drawings, material that is not a real picture), Caption + Picture (refers to real-realistic photos/images), Let's Think (nested text), Exercise, Table, Small Surveys-Tasks, Biology and Daily Life (nested module), Biology... and more Biology (nested module), Illustration without Caption, Annex, Glossary. Also, in cases where there was reference to organisms, the BiTy was applied (Sc.: Scientific, Eco.: Ecologistic, Ut.: Utilitarian, Mor.: Moralistic, Aes: Aesthetics, Dom.: Dominionistic)

Table 1. Recording the references about MB (A-class textbook)

\section{A/A Reference}

Format (Typology)

P.

\section{Syllabus}

Comment - Remark

Figure 2 The "Caption + Picture", i.e. with real images, has a small distribution, while there were only two cases, where

... we have, for example, biological cleaning facilities, that clean the urban wastewater. The ecological

1 disaster of the Argosaronic Gulf, where ends the wastewater of the city of, was reduced thanks to such Text 10 No facilities.

2

Also, thanks to our knowledge of animal biology, fishing Text and hunting are prohibited during the mating season. (Mor.)

10 No

3

Scientific method ... how the storks return to the same Text place every year...

(Sc.)

11 No

In the past there were no scientific explanations for natural phenomena, and people attributed divine or

4 metaphysical attributes to phenomena that could not explain ... and Poseidon with his trident was storming the sea.

\section{Caption +} Illustration (wind and sea with waves)
In caption, we read about Poseidon and trident, but in the illustration represent a wavy sea.

It does not specify where exactly it is mentioned, perhaps

Caption

+ Picture (sea, waves, 16 Yes rocks) students make the impression is that in the sea there are only abiotic objects. 


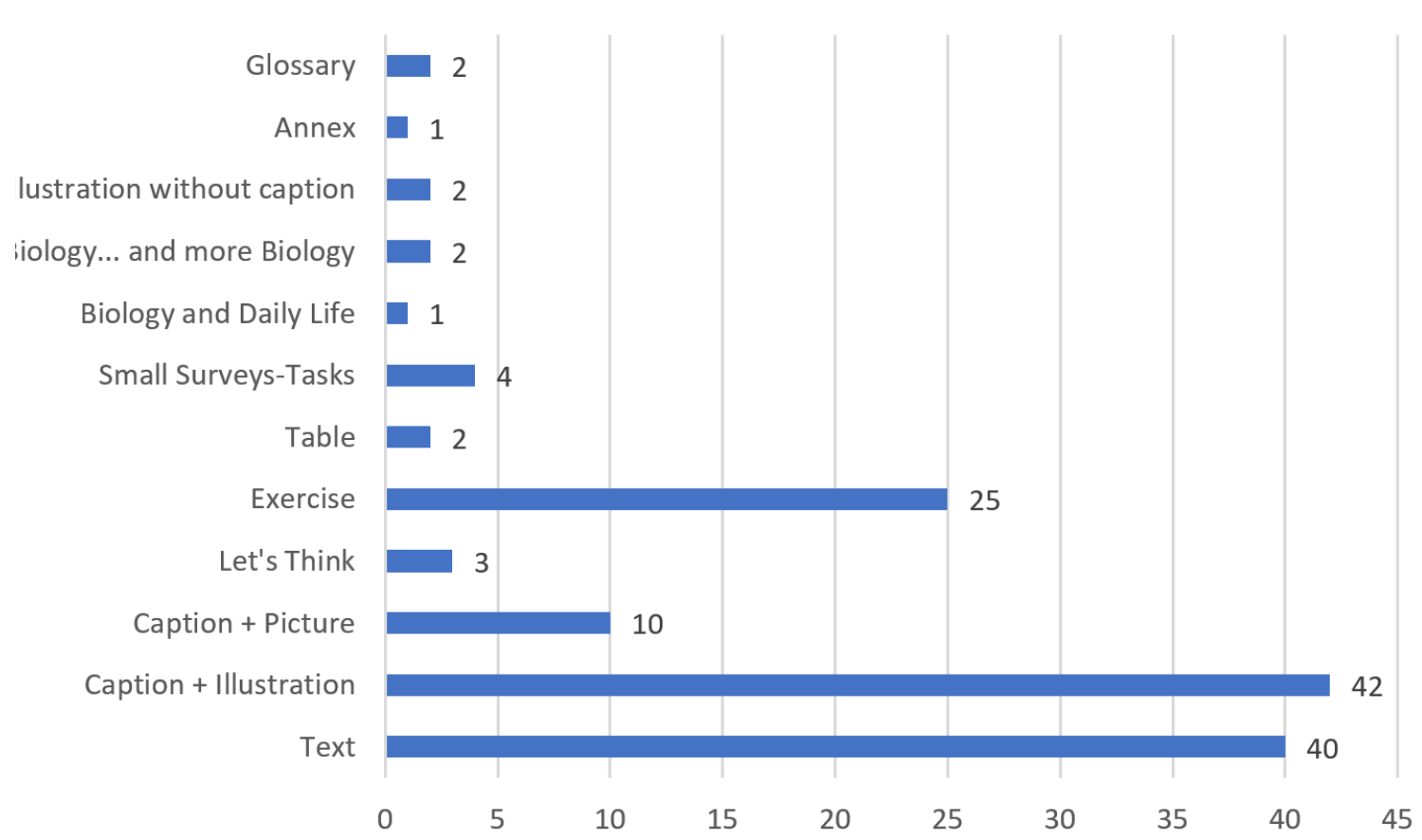

Figure 2. Distribution of recordings according to their format

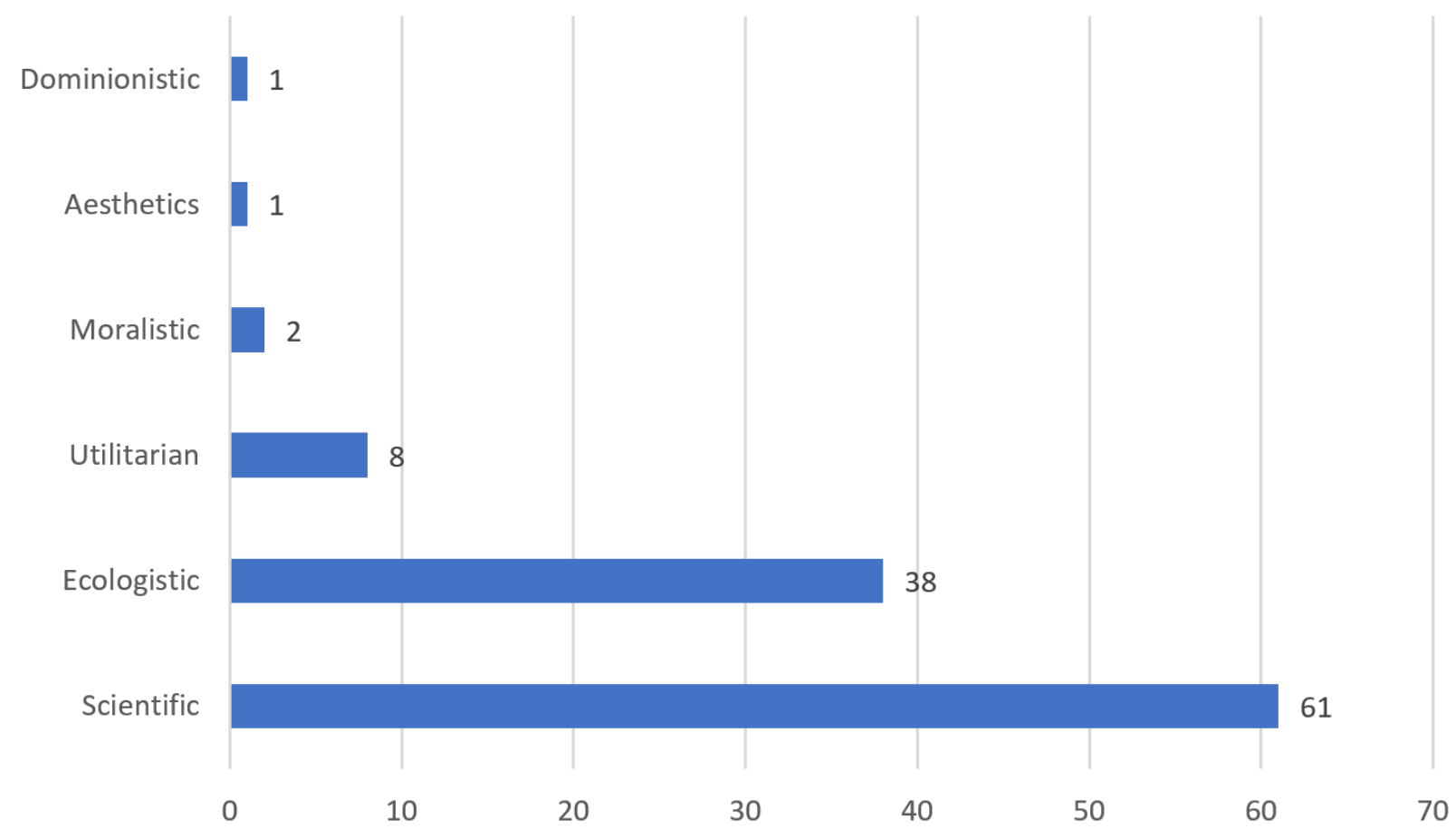

Figure 3. Biophilic Typology (BiTy) results

illustrations without caption were recorded. Therefore, a large part of the information about the MB is found in captions and exercises and not in the text flow of the textbook.

\section{Biophilic Typology}

Figure 3 shows the results of the analysis by applying the BiTy in the cases of the recordings which refer to species (in a total of 108 recordings). It is noted that the Scientific and Ecological optics dominate, while the third in the series is the Utilitarian. The Naturalistic, Humanistic, Negativistic, and Neutralistic are missing.

\section{Syllabus}

81 of 134 recordings (about $60 \%$ ) regarding the MB, taught in the school year 2018-2019, according to the instructions of the Ministry of Education. In the Figure 4 we will see the characteristics of the recordings that have been taught, i.e. their format.

It is noted that a large part of the most frequent 


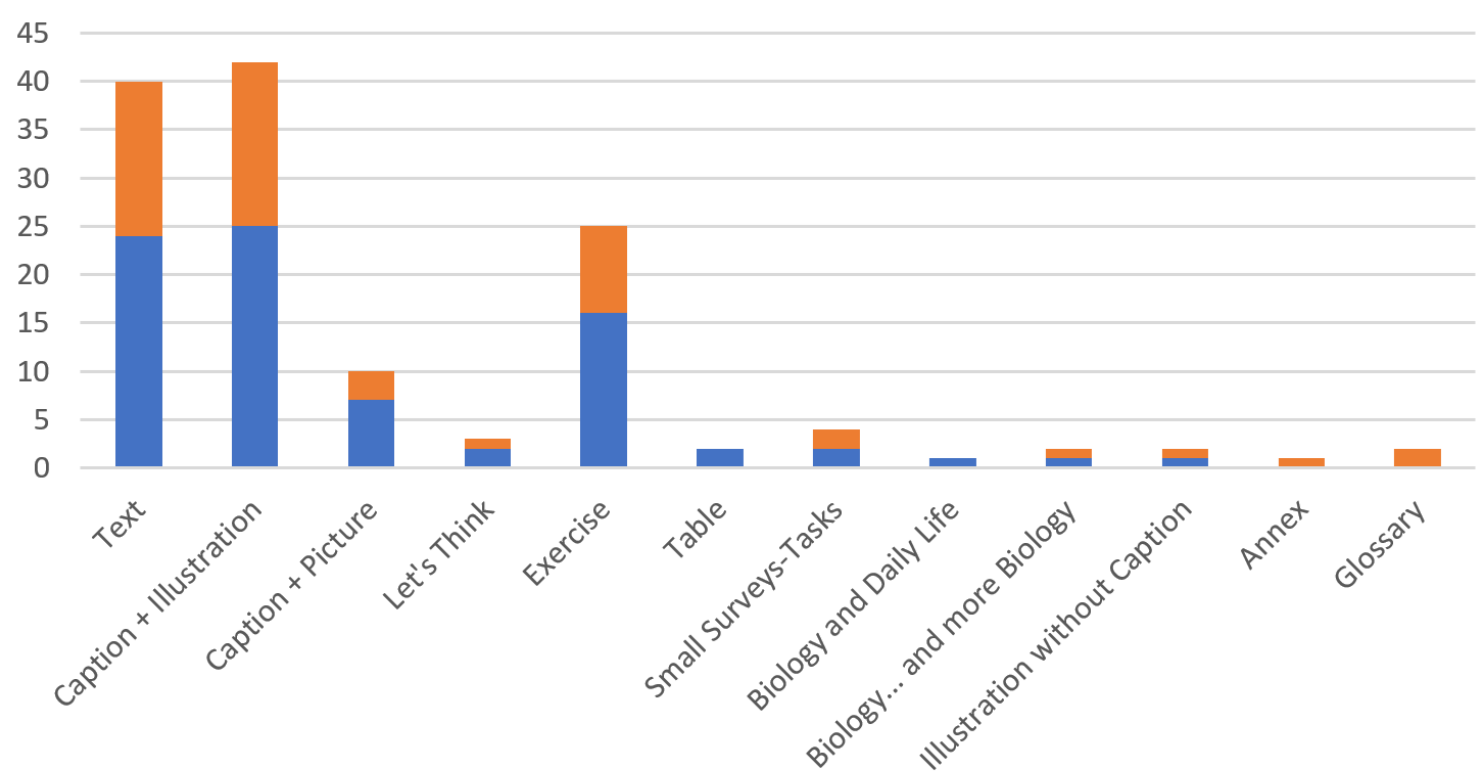

-Yes No

Figure 4. Teaching or not (according the instructions of Ministry of Education), regarding the format

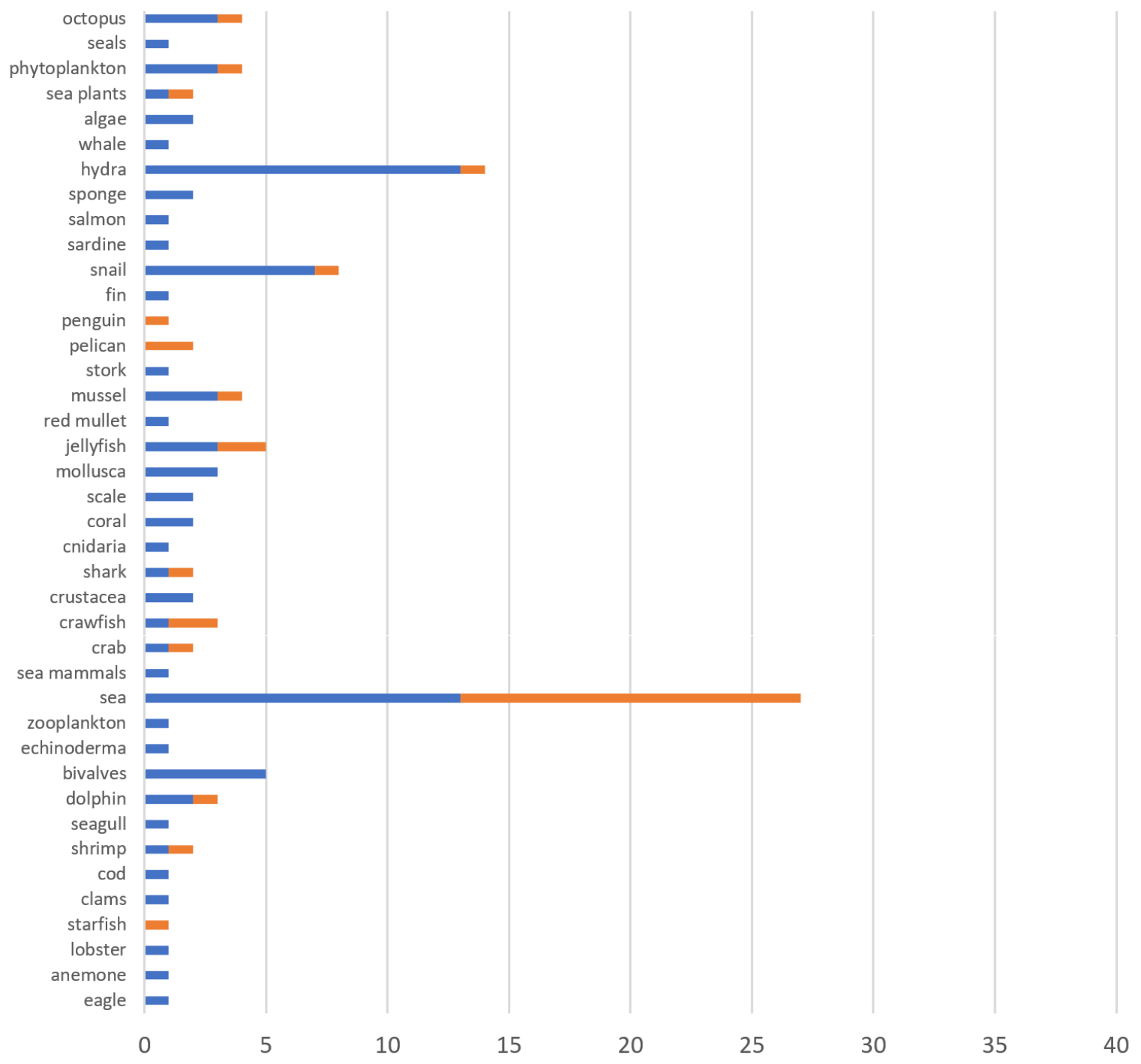

Figure 5. Incidence of Marine Biology concepts - terms 
Table 2. Analytical comments for specific records

\begin{tabular}{|c|c|}
\hline $\begin{array}{l}\text { Lack of } \\
\text { Prior Knowledge }\end{array}$ & $\begin{array}{l}\text { - \#6, although there are algae on the rocks, students cannot recognize them as they have not yet } \\
\text { been taught about them } \\
\text { - } \quad \# 10 \text {, reference to corals without having any prior knowledge for them }\end{array}$ \\
\hline Limited reference & $\begin{array}{l}\text { - \#7, it refers to swimming as a property of fish, while mammals (e.g. whale), birds (e.g. penguin), } \\
\text { etc., can also swim } \\
\text { - \#131, \#132, fossils of marine organisms without figuring out which ones they are, (Ammonite } \\
\text { and Trilobites) }\end{array}$ \\
\hline $\begin{array}{l}\text { Anthropocentric } \\
\text { approach }\end{array}$ & - $\quad \# 18$, stereotype about evil and vicious shark \\
\hline Holistic approach & - $\quad \# 97$, a complete definition of the biosphere that should be taught \\
\hline No added value & $\begin{array}{l}\text { - \#52, \#54, the recording of the 'foot' structure does not offer any added value as it is not men- } \\
\text { tioned or explained elsewhere at this point (only later on, \#72) }\end{array}$ \\
\hline
\end{tabular}

recordings (Text and Caption + Illustration) have not been be taught during the previous school year. Also, interdisciplinary approaches mainly added in the nested entities (Small surveys-tasks, and Biology... and more Biology) had been be excluded from the syllabus. In the Glossary there are two recordings (for the biosphere and eutrophication), both contain positive elements for MB, but it lies in the good intention-will of the teacher for whether to teach them or not.

\section{Use of Marine Biology Concepts - Terms}

Figure 5 shows in detail what terms are used and how often. The use of the terms can be done either directly (clearly stating the term), or indirectly (implied by context or appearing in an image or illustration).

More often the terms 'sea', 'fish' are recorded. There is also a frequent occurrence of the terms 'bivalves', 'jellyfish', 'mussel', 'snail', 'hydra'. The sea animals that are mentioned are the following: eagle, anemone, lobster, starfish, clams, cod, shrimp, seagull, dolphin, zooplankton, crab, crayfish, shark, coral, jellyfish, red mullet, mussel, stork, pelican, penguin, snail, sardine, salmon, sponge, hydra, whale, algae, phytoplankton, seals, octopus, all of course at very low frequencies.

\section{Number of Pages}

The textbook of the A class of Gymnasium consists of approximately 150 pages. For MB there is at least one record to 53 different pages. The textbook of the $B, C$ classes of Gymnasium consists of about 140 pages. For MB there is at least one record to 25 different pages.

\section{Data from The Comments-Observations of The Recordings}

In the analysis of the recordings, several points were found which were considered to require further commentary (See details in Supplementary Material). In Table 2, specific examples per category, are presented (the numbers\# correspond to the recordings' serial number): In several words, phrases or even sentences, there are weaknesses that teachers should consider during their teaching process.

\section{DISCUSSION}

By analyzing in different ways, the textbooks taught in secondary compulsory education, we observe positive elements, negative ones and possibly some shortcomings that may complicate rather than favor learning. Overall, however, there is an attempt to present MB issues, but not in an organized way and usually this is not observed through a matter of central choice but as an exception or an extension of other subjects.

The most positive of the analysis is that most references to MB, according to the BiTy, are incorporated in the Ecological and Scientific perspective. Thus, students in these cases are taught the living beings of the seas as well as their biological processes as components of the natural world, with selected and distinct functions at both individual-physiological level and in ecological and environmental coexistence. Structures with a distinct biological role are presented or identified, often explained and integrated into the common functions of all organisms. In addition, scientific concepts of MB are introduced which we can accept that at least they provide the appropriate stimuli to the pupils in order to the presence of an additional world, rich in form, functions and species, within seas. Even the Utilitarian perspective, when applied, offers an understanding of the benefits of the use of marine organisms, both for people and for the wider environment.

However, even these reports are limited and usually of a small extent. In the A-class of Gymnasium a broader 
presentation is made, corresponding to a larger a larger proportion of pages in the textbook. It is impressive that much information is found in picture captions, that is, parts of the textbook that is not certain that they will be taught. Even if the recorded reports are within the basic body-text of the textbook, according to the Ministry's instructions a large part (around 1/3) of this syllabus have not been taught in the school year 2018-2019. There are reports of exercises where students are often asked to respond based on experiential-empirical knowledge and not based on knowledge gained from the pages of the textbook. It is legitimate to use experiential knowledge, but it is not certain that in the learning process has been tested for its scientific correctness (Voukelatou, 2019; Karpudewan \& Khan, 2017).

It is also interesting that a large part of the recordings (about 40\%) according to the Ministry's instructions have not been taught to Gymnasium students the previous academic year. If we consider that from those that will be taught ( 81 from 134) only 24 are contained in the text of the textbook, we understand that a small percentage is contained in the syllabus. The other recordings to be taught (57 recordings in the form of captions in illustration, exercise, biology and daily life, etc.) depend on the teacher's choice whether to teach them, since it is known that the textbook is the basic teaching tool and teachers usually choose to teach the parts of the basic text.

The term "fish" is widely used. This term, from biological-taxonomic is very generic and includes a multitude of groups (taxa) without itself being part of a group (taxon). This is a paraphyletic group with no special importance in classification and taxonomy. On the other hand, terms (taxa) such as Cnidaria, Mollusca, Echinoderms, Crustaceas with biological-taxonomic interest are not analyzed. They are presented as general groups with references to their representatives, but without highlighting their characteristics and grouping which makes them important taxonomic group among marine animals. Even the distinction between vertebrates and invertebrates presented from the beginning of the textbook, are clarified much later.

In other points, the recording is done in a way that if that at least restricts the critical thinking of the student if not excluding it. So, students read about carbon dioxide intake 'from the air' or the release of oxygen 'in the air', limiting the possibility of them being dissolved in water. Another case is that swimming is mentioned as a fish property, while other aquatic organisms can swim as well. It is important that there is a lack of reference to marine organisms' fossils (Ammonite, Trilobites) in the recordings of the C-class, while in the recording of 119 for the environmental pollution, the reference is limited to the problems that it creates in people ignoring the permanent residents of the aquatic ecosystems, i.e. the marine organisms. In the chapter of plant reproduction there are not any references to marine plants, while there is a limited reference to algae, this wealth of marine ecosystems. The reproduction of the stereotype of the vicious shark as well as the image of dolphins from a non-natural environment, which create very mistaken impressions for both the behavior of the species as well as the inappropriateness of their confinement in nonnatural environments, should also be noted.

For the most effective and comprehensive teaching of $\mathrm{MB}$, it would be necessary to enrich the curricula and the corresponding textbooks with more references, since they are limited and this is also valid internationally (Fauville, Copejans, \& Crouch, 2013). However, the Greek reality proves that this is not feasible, since both the curricula and the corresponding textbooks change and are transformed after many years, along with several barriers that are generally observed in Europe (Fauville et al., 2018). With the existing educational material, efforts could be made to at least achieve better teaching of the knowledge mentioned in the textbook. Towards this direction, teachers should firstly enrich their teaching not only with the text but with the other points-formats of material that we have identified as referring to the MB. So the captions in the illustrations should be analyzed, the exercises should be clarified in terms of their content since in several cases they require experiential knowledge, while in cases where there are images or illustrations without information, the missing information should be given to the students. The prefixes and modules for additional biology, should be able to be included in the teaching and be derived from these stimuli for further discussion and interaction.

The introduction of the courses should precede a basic discussion on the classification and basic taxonomic groups of marine organisms (Kvist, Montanari, Yi, Fuk, \& Siddall, 2011). The teaching intervention of teachers could be confined to the taxa mentioned, so that at least the above, could be perceived from the students as well as their association and their basic characteristics. Thus, for example, the use of the terms 'animals', 'plants' and for marine organisms will be broadened, while the term 'fish' which is so often used and may cause problems will be clarified. Moreover, more extensive reference could be made, even from examples of everyday life, to many of the animals mentioned, such as the jellyfish, and for which there are incorrect scientific opinions among students. Finally, in an educational context (textbooks, classroom teaching, syllabus) these animals should be linked to their ecology and their environment and not be dealt 
just as food to eat, while the evolutionary perspective should be included in the teaching process (Stasinakis \& Athanasiou, 2016; Stasinakis \& Kampourakis, 2018). In that way, students will be able to link the animals with the environmental problems and the degradation of marine ecosystems, aiming at changes attitudes and behavior that are essential objectives in biology courses (Kollmuss \& Agyeman, 2002).

Digital material available at Fotodentro (Stasinakis, 2016; Katsaros \& Stasinakis, 2020) could be used, although in cases where it is easy to access a marine ecosystem to study, the visit is a preferable option. The students of a country, like Greece, who come so often in contact with the sea, should associate with the biology of the organisms that live in it so that they can enjoy it with a more sustainable approach, consider it as an important social issue (Longo \& Clark, 2016).

The teaching should be accompanied by a corresponding teacher education as it is found (Linsky, 2017; Boubonari, Markos, \& Kevrekidis, 2013) that teachers usually have similar misconceptions or are partially aware of the taught objects, like their pupils. In addition, the research shows (Boubonari, Markos, \& Kevrekidis, 2013) that even the future teachers have partial knowledge even about the pollution of the seas, furthermore they have also common misconceptions. The findings and experience converge on the need to educate pre- and in-service teachers on marine ecosystems and their preservation.

In the next stage of our research, the primary education textbooks will be analyzed and the results will be compared with these of the current study. In addition, the aim is to create educational material, the use of which by the teachers could help teaching, aiming at a more effective engagement of the students with MB. The produced educational material will be evaluated and will be the starting point of an effort to improve the existing situation, enriched with lesson plans and activities. Finally, by using an appropriate questionnaire we will try to record the views of the students regarding the organisms and functions of the marine life. Let us remember the labeling of Earle (1995): 'If The sea is sick, we'll feel it. If It dies, we die. Our Future and the state of the oceans are one'. (p. xii).

\section{ACKNOWLEDGEMENTS}

I am grateful to Dr. Eleni Voultsiadou, Professor, Aristotle University of Thessaloniki, Faculty of Sciences, School of Biology, Department of Zoology, Laboratory of Zoology, for her help about bibliography of the Greek sea, and her reading in a draft version of this paper. She also helped me to clarify MB terms. I would like also to thank
Dr. Evdokia Protopadakis for her useful feedback and her remarks on the article.

\section{REFERENCES}

Arvanitidis, C. (2018). The marine biodiversity of Greece. The Nature, Hellenic Society for the Protection of Nature, 159160. [Greek text].

Berelson, B. (1952). Content analysis in communication research. New York: Free Press.

Boubonari, T., Markos, A., \& Kevrekidis, T. (2013). Greek preservice teachers' knowledge, attitudes, and environmental behavior toward marine pollution. The Journal of Environmental Education, 44(4), 232-251. https://doi.org/ 10.1080/00958964.2013.785381

Burgess, D. J., \& Mayer-Smith, J. (2011). Listening to children: Perceptions of nature. The Journal of Natural History Education and Experience, 5, 27-43.

Chapman, R.L. (2013). Algae: the world's most important "plants"-an introduction. Mitig Adapt Strateg Glob Change, 18, 5-12. https://doi.org/ 10.1007/s11027-010-9255-9

Donert, K., Fauville, G., Gotensparre, S., Mäkitalo, Å., Van Medegael, L., \& Zwartjes, L. (2015). Review of marine formal education, EU Sea Change Project. Retrieved from https:// bit.ly/3pgxsCk

Earle, S. A. (1995). Sea change: A message of the ocean. New York: Putnam.

Fauville, G., Copejans, E., \& Crouch, F. (2013). European marine educators, unite! Europe's quest for a more ocean-oriented society and economy. The Marine Biologist, 1, 30-31.

Fauville, G., McHugh, P., Domegan, C., Mäkitalo, Å., Møller, L., Papathanassiou, M., Chicote, C., Lincoln, S., Batista, V., Copejans, E., Crouch, F., \& Gotensparre, S. (2018). Using collective intelligence to identify barriers to teaching 12-19 year olds about the ocean in Europe. Marine Policy, 91, 8596.

Hellenic Phycological Society. (2008). A dip, a look at the water gardens. Knowing the algae, HEL.P.S: Athens. [Greek text].

Hellenic Statistical Authority (2018). Hellas with numbers-JulySeptember 2018, Retrieved from https://bit.ly/34AuJMq [Greek text].

Karpudewan, M., \& Khan, A.M.S.N. (2017). Experiential-based climate change education: fostering students' knowledge and motivation towards the environment. International Research in Geographical and Environmental Education, 26(3), 207-222. https://doi.org/ 10.1080/10382046.2017.1330037

Katsaros, N.A., \& Stasinakis, P.K. (2020). Using Aipotu simulation to promote evolution learning and teaching. Biochemistry and Molecular Biology Education, 48, 433-435. https://doi. org/10.1002/bmb.21385

Kellert, S. R., \& Westervelt, M. O. (1983). Children's attitudes, knowledge and behaviors toward animals: Phase V. United States Department of the Interior Fish and Wildlife Service.

Kim, J.-M., Anderson, D., \& Scott, S. (2013). Korean elementary school students' perceptions of relationship with marine organisms. Asia-Pacific Forum on Science Learning and Teaching, 14(2). Retrieved from http://bit.ly/3mI9tKA

Kollmuss, A., \& Agyeman, J. (2002). Mind the gap: Why do people act environmentally and what are the barriers to pro-environmental behavior?. Environmental Education Research, 8(3), 239-260.

Kvist, S., Montanari, S.A., Yi, H., Fuks, B., \& Siddall, M.E. (2011). Teaching biodiversity \& evolutionary biology in a North 
American marine coastal environment. The American Biology Teacher, 73 (2), 72-77. https://doi.org/10.1525/ abt.2011.73.2.4.

Liarakou, C. (2008). Why protect endangered species? Analysis of the approaches adopted by the students of Gymnasium of Samos for the protection of the jackal. Pedagogical currents in the Aegean, 3, 94-105. Retrieved from https:// goo.gl/5wwqGD. [Greek text].

Linsky, C.L. (2017). "Sure, I can read an ocean book:" Teacher's misconceptions about ocean literacy'. Current: The Journal of Marine Education, 31 (1), 11-15.

Longo, S.B., \& Clark, B. (2016). An ocean of troubles: Advancing marine sociology. Social Problems, 63(4), 463-479.

Mavrikaki, E., Gouvra, M., \& Kabouri, A. (2016a). Textbook - biology for a-class of gymnasium. Athens: Institute of Computer Technology and publications Diofados.

Mavrikaki, E., Gouvra, M., \& Kabouri, A. (2016b). Textbook biology for b-\& c- class of Gymnasium. Athens: Institute of Computer Technology and publications Diofados.

Mironaki, A. (2016). The marine biology as word and image in the curriculum and textbooks for primary and secondary education: an interdisciplinary teaching approach. PhD thesis, University of the Aegean, Faculty of Humanities, Department of Pre-school Education and Educational Design, Retrieved from https://www.didaktorika.gr/eadd/ handle/10442/39231. [Greek text].

Sakurai, R., Uehara, T., \& Yoshioka, T. (2018). Students' perceptions of a marine education program at a junior high school in Japan with a specific focus on Satoumi. Environmental Education Research, 25(2), 222-237. https:// doi.org/10.1080/13504622.2018.1436698.

Stasinakis, P. K. (2009). Knowing the algae, the leaf environmental sensitivities. Hellenic Society for the Protection of Nature, 8, 4-10. [Greek text]

Stasinakis, P.K., \& Koliopoulos, D. (2009). Analysis of biology textbooks in secondary education: The case of plant and animal nutrition. Science and Technology Issues in Education, 2(1-2), 103-125. Available online at: http://bit.ly/2SFNQOn, Last accessed February 8, 2020. [Greek text]

Stasinakis, P., \& Athanasiou, K. (2016). Investigating Greek biology teachers' attitudes towards evolution teaching with respect totheirpedagogical contentknowledge:suggestions for their professional development. Eurasia Journal of Mathematics, Science \& Technology Education, 12(6), 16051617. https://doi.org/10.12973/eurasia.2016.1249a.

Stasinakis, P. (2016). The characteristics of biology, as a challenge for the using of ICT in biology teaching. Neos Paidagogos, 7, 172-187, ISSN: 2241-6781. [Greek text]

Stasinakis, P.K., \& Kampourakis, K. (2018). Teaching evolution in Greece. In H. Deniz, L. Borgerding (Eds.), Evolution Education Around the Globe, Dordrecht: Springer, eBook ISBN: 9783-319-90939-4, Hardcover ISBN: 978-3-319-90938-7, https:// doi.org/10.1007/978-3-319-90939-4.

UH (2018). 3rd National Report on the implementation of Directive 92/43/EEC. Retrieved from http://bit.ly/20Cff2l. [Greek text].

Van Bressem, M.-F., Alfaro-Shigueto, J., Geysen, K., Onton, K., Vega, D., Chavez-Lisambart, L., \& Van Waerebeek, K. (2006). Dolphins and children: A blueprint for marine environmental education in Peru. Applied Environmental Education and Communication, 5, 183-191.

Van den Born, P. J. G., Lenders, R. H. J., De Groot, W. T., \&
Huijsman, E. (2001). The new biophilia: An exploration of visions of nature in Western countries. Environmental Conservation, 28(1), 65-75.

Voukelatou, G. (2019). The contribution of experiential learning to the development of cognitive and social skills in secondary education: A case study. Education Sciences, 9, 127. https://doi.org/10.3390/educsci9020127

Voultsiadou E., Gerovasileiou V., \& Dailianis, T. (2013). Extinction trends of marine species and populations in the Aegean Sea and adjacent ecoregions. pp. 59 - 74 in CIESM Workshop Monograph $\mathrm{n}^{\circ} 45$ [F. Briand, ed.] Marine extinctions - patterns and processes, 188 p., CIESM Publisher, Monaco. 